\title{
Mineral self-organization in anoxic conditions: a window into early Earth geochemistry and prebiotic chemical reactions
}

\author{
ELECTRA KOTOPOULOU ${ }^{1}$, ALEJANDRO FERNANDEZ- \\ MARTINEZ $^{2}$, ALEXANDER E.S. VAN DRIESSCHE ${ }^{2}$ AND \\ MARCO DI MICHIEL ${ }^{3}$ \\ ${ }^{1}$ Universite Paris-Saclay - CNRS \\ ${ }^{2}$ ISTerre, Univ. Grenoble-Alpes, CNRS \\ ${ }^{3}$ ESRF - The European Synchrotron \\ Presenting Author: geoelectra.kotopoulou@gmail.com
}

Self-organized, iron-silica(te) tubular membranes (commonly known as chemical gardens) are thought to have served as electron/proton conductors and redox catalysts in early Earth alkaline hydrothermal systems that have been proposed as possible niches for the emergence of metabolic reactions [1-3]. These membranes made of iron nanoparticles over an amorphous silica support can, among others, i) behave as fuel-cells, generating an electrochemical potential in the range of 500-600 $\mathrm{mV}$, ii) catalyze the formation of amino-/carboxylic acids and RNA nucleobases from simple organics that were available on early Earth (i.e. formamide $\left(\mathrm{CH}_{3} \mathrm{NO}\right)$ and pyruvate $\left(\mathrm{CH}_{3} \mathrm{COCO}_{2}^{-}\right)$, iii) act as an effective shield against UV radiation, and iv) form bilayers [4-7]. These properties are directly related to their chemical and mineralogical composition [7].

Yet, the available information on the chemistry and mineralogy of iron-silica membranes -and chemical gardens in general-, comes from experiments/analyses performed in presence of oxygen. Thus, investigating their formation and composition in anoxic conditions, such as those prevailing in early Earth, is of paramount importance for: i) understanding their possible key role in prebiotic chemical reactions of the Hadean Earth, and ii) distinguishing them from early Archean iron filamentous microfossils found in cherts and silica-rich precipitates.

To bridge this knowledge gap we performed ferrous iron-silica membranes growth in capillaries, inside a glovebox chamber, and characterized them at the nanoscale using high-energy X-ray scattering experiments (coupled to Pair-distribution function analysis), maintaining the sample in anoxic atmosphere. Here, we will discuss the preliminary results on the organization and mineralogy of these membranes in anoxic conditions, and their implications for early Earth mineralogy, prebiotic chemistry and life detection on Earth and beyond.

References

[1] Russell M.J, Hall A.J., (1997) J. Geol. Soc. Lond. 154, 377-402.

[2] Preiner, et al., (2020) Nat. Ecol. Evol. 4, 534-542.

[3] Garcia-Ruiz et al., (2017) Sci. Adv, 3, e1602285.

[4] McMahon, (2019) Proc. R. Soc. B. 286, 20192410.

[5] Saladino et al., (2016) Biochemistry 55, 2806-2811.

[6] Barge et al., (2019) PNAS 116, 4828-4833. 